\title{
GUATEMALA: EL PAPEL DE LOS MEDIOS EN EL DEBATE PÚBLICO
}

\author{
GUATEMALA: THE ROLE OF MEDIA IN THE PUBLIC DEBATE
}

Ana Silvia Monzón

Linda García Arenas

Recibido: 19-09-2018 - Aceptado: 29-10-2018

\begin{abstract}
Resumen
El artículo plantea brevemente algunas categorías que orientan la exposición, ubicando el concepto de debate u opinión pública centrada en los medios de comunicación y vinculándolo con la historia guatemalteca en las últimas tres décadas. Este período abarca el fin formal del conflicto armado interno hacia 1985, la firma de los Acuerdos de Paz, en 1996, el cual abrió la expectativa de una efectiva democratización de las instituciones, de la ciudadanía y, por supuesto, de los medios de comunicación, hasta entonces muy limitados en el ejercicio de un periodismo investigativo y crítico, y el deterioro de las instituciones estatales que, sobre todo en los últimos cinco años, han empezado a tener impacto en la opinión pública crítica (medios alternativos e independientes) y han reforzado un esquema de colusión entre los intereses partidarios y los medios, el cual ha contribuido a pervertir la democracia en el país.
\end{abstract}

Palabras clave: Medios de comunicación, democracia, medios alternativos, política, Guatemala.

\begin{abstract}
The article briefly presents some categories that guide the exposure, placing the concept of debate or public opinion centered on the media, and linking it with Guatemalan history in the last three decades. This period covers the formal end of the internal armed conflict towards 1985, the signing of the Peace Agreements in 1996, which opened the expectation of an effective democratization of institutions, citizenship and, of course, the media, until then very limited in the exercise of investigative and critical journalism, and the deterioration of state institutions that, especially in the last five years have begun to have an impact on critical public opinion (alternative and independent media), and have reinforced a scheme of collusion between the interests of political parties and the media, which has contributed to pervert democracy in the country.
\end{abstract}

Keywords: Media, democracy, alternative media, politics, Guatemala. 


\section{Introducción}

En las últimas tres décadas, la historia de los medios de comunicación en Guatemala y su papel en el ámbito público están marcados por varios matices. Lejos de significar democracia y pluralidad de voces, trae connotaciones de propiedad privada, monopolios y concentración de la riqueza, asimismo, de una política estatal de represión y violación de los derechos de libertad de pensamiento, de expresión y opinión, tanto de las ciudadanas y ciudadanos, como de los medios que siguen una línea crítica.

En efecto, a pesar de la apertura que significó la transición a un régimen civil en la segunda mitad de los años ochenta, el cual avanzó con la firma de los Acuerdos de Paz, los grandes medios continuaron reproduciendo una visión hegemónica y homogénea del país, sin lugar para la diferencia, ni para la diversidad de identidades, estéticas, pensamientos y propuestas. No obstante, los mismos acuerdos reconocieron tanto el carácter multicultural, pluriétnico y plurilingüe de la sociedad guatemalteca, como una agenda basada en el enfoque de derechos humanos, al incorporar las demandas de las mujeres y de los pueblos indígenas.

Contrario al espíritu de estos acuerdos, continúa la reproducción de jerarquías de poder, brechas de género y etnia, de manera que los discursos, imaginarios y representaciones sociales transmitidas por la mayoría de medios siguen siendo parciales y sesgados. A esto se suma la imbricación entre los intereses de la clase política, caracterizada por el caudillismo, y no por liderazgos democráticos, y de las élites económicas, autoritarias y excluyentes, con la dinámica de los medios masivos de comunicación. De manera que la tendencia ha sido el fortalecimiento de los entramados de poder, incluido el poder mediático.

A pesar de este panorama sombrío, emergen iniciativas comunicacionales desde la crítica, desde pensamientos y voces disidentes que comunican las luchas y acciones de comunidades y movimientos sociales que toman la palabra, elaboran y difunden sus narrativas, entran en la disputa de sentidos, de discursos, desde la contra hegemonía, medios que resignifican desde la resistencia y desde la historia propia.

Esas facetas son abordadas en este artículo, el cual presenta una mirada panorámica de un campo que está en continuo movimiento, donde la pluralidad de opiniones y el libre ejercicio de los derechos a la expresión y a la comunicación por momentos avanzan, o bien, como en la actual coyuntura, más bien retroceden. La exposición se sustenta en la historización que permite aproximarse a la trayectoria histórica, en este caso de los medios, en el contexto de la sociedad guatemalteca en las últimas tres décadas, de los años noventa a la actualidad. La técnica utilizada fue básicamente la revisión y análisis documental.

El artículo plantea inicialmente algunas categorías que orientan la exposición. En primer lugar, ubica el concepto de debate u opinión pública centrada en los medios de comunicación y vinculándolo con la historia guatemalteca en las últimas 
tres décadas. Este período abarca el fin formal del conflicto armado interno que por casi cuatro décadas marcó la dinámica social, política y económica del país, y que incluye la promulgación de una nueva Constitución en 1985, y la elección de un presidente civil después de varios gobernantes militares.

Posteriormente, se encuentra la discusión y firma de los Acuerdos de Paz, en 1996, que abrió la expectativa de una efectiva democratización de las instituciones, de la ciudadanía y, por supuesto, de los medios de comunicación, hasta entonces muy limitados en el ejercicio de un periodismo investigativo y crítico. Finalmente, el crecimiento de los medios de comunicación en el período posterior a la firma de los acuerdos, en el cual se marca una apertura sin precedentes en los primeros años, pero también se va desarrollando un esquema de colusión entre los intereses partidarios y los medios, que ha contribuido a pervertir la democracia en el país, como fue evidenciado en un informe inédito elaborado por la Comisión Internacional contra la Impunidad en Guatemala (CICIG).

Se presenta un breve perfil de los medios que actualmente tienen presencia en el país. Luego, en el cierre se presentan los desafíos para el ejercicio de una opinión pública crítica, tanto para los medios como para la ciudadanía y los movimientos sociales.

\section{La comunicación política y los medios de comunicación: Aspectos conceptuales}

En la comunicación política, campo disciplinario que entrecruza la ciencia política, la sociología política y la comunicación, el concepto de opinión pública ocupa un lugar central. Según Pareja y Echeverría, este puede comprenderse como "un fenómeno social en que existe una serie de ideas, pensamientos, creencias en torno a diversos temas de carácter colectivo" (52).

En las sociedades modernas, cuyo régimen político es la democracia, es necesaria la existencia de espacios para que la ciudadanía sea "capaz de formar una opinión pública por medio de la discusión crítica, la argumentación razonada y el debate" (Pareja y Echeverría 53). Sin embargo, este derecho a pensar, discutir e intervenir en asuntos de carácter público está mediado por la asimetría del poder, de manera que solo unos pocos, generalmente hombres, de las élites, de determinado grupo étnico, del área urbana y de los centros de poder, pueden influir e imponer sus criterios, manejando la opinión pública a favor de sus intereses, en detrimento de la mayoría de ciudadanos y ciudadanas.

En esta dinámica social y política, los medios de comunicación constituyen el vehículo para el ejercicio de ese poder, sobre todo a partir del siglo veinte, cuando los medios experimentaron una verdadera revolución tecnológica caracterizada por la integración entre informática, telecomunicaciones y redes, cuyo impacto en las formas y contenidos de la comunicación llegan a tener un alcance global. 
Los medios van ocupando un lugar preponderante en la circulación de información, datos y noticias, así como en la construcción y difusión de las identidades (étnico-culturales, sexuales, de género, políticas, entre otras); asimismo, en los sistemas de representación social. Este desarrollo se da, en parte, como resultado de la concentración, vertical y horizontal, de la propiedad de los medios (Monzón 17) que convierte la comunicación en mercancía, desde una lógica de homogeneización y estandarización de discursos, narrativas, imágenes, estéticas, patrones de consumo y modos de vida.

El monopolio económico característico del capitalismo, ahora globalizado, se imbrica con el reforzamiento de las estructuras de poder patriarcales, socioraciales y neocoloniales, lo cual impone "una cultura mundial" que pretende reducir las expresiones culturales a "marcas" que se pueden comprar y vender, dejando de lado la comunidad, la historia y las tradiciones propias. Hay un despojo cultural, discursivo, incluso lingüístico, con una clara desventaja para los países con escaso desarrollo tecnológico y mediático y para amplios grupos sociales que son excluidos del mainstream mediático. Si bien estos continúan elaborando sus propias miradas de mundo, generalmente críticas, lo hacen desde la marginalidad.

Tanto en el campo de la cultura, como de la política, los medios de comunicación vinculados con la esfera del poder moldean la opinión pública. De acuerdo con Pareja y Echeverría:

En esta lógica se inscribe uno de los paradigmas clave de la relación medios y opinión pública: el de la teoría del Agenda Setting, la cual describe el papel de los medios de comunicación de masas como actores politicos que estructuran la realidad a partir de su jerarquización. A través de la organización diaria de la realidad social y politica, los medios influyen en el establecimiento de los asuntos sociales alrededor de los cuales el público forma su acervo temático (54).

La comunicación política, la opinión pública y los medios de comunicación constituyen el campo social de disputa de poder, donde se van perfilando dos espacios de opinión pública: uno manipulado y otro crítico. Uno ligado a las estructuras de poder y el otro resistiendo, desafiando, impugnando y deconstruyendo ese poder, a la vez que afirma su propia mirada de mundo. Entre esos espacios se aprecian matices que dan cuenta de la dinámica de la comunicación humana, social y política, de los resquicios del poder, dado que este no siempre es absoluto.

Desde esa perspectiva se abordará el papel de los medios en Guatemala, en el período entre los años noventa y la actual coyuntura. Por supuesto no es una mirada exhaustiva, sino una aproximación al desarrollo de los medios a partir de una revisión documental. 


\section{Los medios. Su papel en la agenda mediática en Guatemala}

Existen varias interpretaciones acerca del papel de los medios de comunicación en la sociedad; mientras alguna corriente los caracteriza como un reflejo de lo que sucede en una sociedad, otros plantean que los medios no son neutrales, ya que no solo difunden noticias y construyen discursos que tienen efectos en el contexto social, sino también son actores políticos con influencia en la agenda pública (Califano). Es decir, los medios están inmersos en entramados de poder y en el último siglo han adquirido una enorme presencia tanto a nivel social como en la vida cotidiana. Lo transmitido por los medios goza de legitimidad, como antes sucedía con instituciones como la universidad, la iglesia, el ejército y el Estado, "porque el público cree en lo que se oye y se ve a través de ellos... los medios avalan hechos, situaciones, opiniones y personas" (López Vigil 23).

En efecto, los medios tienen ese poder de visibilizar o invisibilizar, de dar relevancia a unos hechos y no a otros, de instalar en la opinión pública determinadas facetas de una situación y dejar fuera otras. Realizan este ejercicio basándose en una pretendida objetividad que no es tal cuando se devela cuáles son sus intereses, fuentes de financiamiento y agenda. Los medios se plantean como el mecanismo para intermediar entre quienes gobiernan y la ciudadanía; no obstante, en la realidad, dado el carácter privado de los grandes medios, actúan como empresas que "fabrican noticias" (Fischman, citado por Califano). Esa producción de noticias se basa en criterios de mercado, orientan las percepciones de quienes "consumen" esos productos noticiosos, sin entrar a contrastar con otras fuentes de información, ni a profundizar en los datos que ofrecen los medios.

Los medios de comunicación abarcan todos los órdenes de la vida social: la educación, la salud, la economía, los derechos, la cultura, la recreación, los deportes, la alimentación, la recreación, entre otros; sin embargo, lo hacen generalmente desde una mirada acrítica. Desde una perspectiva mercadológica, los medios han ido perfilando una segmentación de públicos, lo cual ha diversificado la oferta noticiosa e informativa, sin que esto implique el desarrollo de una conciencia ciudadana, por el contrario, se profundiza la visión de que quienes reciben la información son solo individuos que consumen información.

\section{Lo rural, las mujeres y los pueblos indígenas excluidos del mainstream mediático}

Los medios de comunicación se han convertido en la fuente principal para formarse una idea de la realidad, de ahí su enorme influencia en amplias capas de la población, sobre todo del área urbana. Asimismo, en sus espacios se reproducen los ejes de poder y la dinámica de inclusión/exclusión que tiende a privilegiar, como acontecimiento, lo que sucede en los espacios urbanos y cercanos a los centros de 
poder, y a excluir los hechos que ocurren en el área rural, especialmente en los lugares más alejados. La inclusión de noticias locales en los grandes medios es relativamente reciente en los medios escritos y se ha ido incorporando también en los medios radiofónico, televisivo y digital. Sin embargo, salvo que se trate de desastres, accidentes o protestas sociales, lo que sucede en el ámbito local no ocupa grandes espacios, ni portadas o editoriales.

En esta lógica se sitúan las mujeres y los pueblos indígenas, quienes, a pesar de constituir la mitad de la población, aparecen con poca frecuencia en los medios como fuentes de información o como protagonistas de noticias donde se valoren sus aportes a la sociedad. En un estudio realizado por Cerigua se concluye que:

La información sobre las mujeres en los distintos medios de comunicación es regateada y escasa, usualmente, cuando son protagonistas en las páginas de prensa son visibilizadas como víctimas de sucesos trágicos o mostradas como símbolos sexuales para la comercialización de distintos productos (s. p.).

En el mismo sentido, la socióloga Silvia Trujillo plantea que el Observatorio Mujer y Medios contribuyó a evidenciar, a través de un ejercicio de monitoreo sistemático de medios, cómo las mujeres, en general, y las mujeres mayas, en particular, estaban excluidas de los medios o expuestas desde una "falsa visibilización" para ilustrar temas como "el atraso, la pobreza, la tragedia". No como ciudadanas o como sujetas de información.

En el caso de los pueblos indígenas, la situación es similar, el racismo estructural que prevalece en la sociedad guatemalteca también se expresa en los medios, de manera que se invisibiliza o folkloriza a la población maya, afrodescendiente, garífuna y xinca, lo cual difunde la imagen y el discurso de un país monolingüe y monoétnico, que ha sido construido, como plantea la académica Martha Casaús, desde:

La valoración generalizada y definitiva de unas diferencias biológicas o culturales, reales o imaginarias, en provecho de un grupo y en detrimento del otro, con el fin de justificar una agresión y un sistema de dominación. Estas actitudes pueden expresarse como conductas, imaginarios, prácticas o ideologías que como tales se expanden a todo el campo social formando parte del imaginario colectivo (13).

El rol de los medios para difundir y reproducir ese imaginario colectivo es de primer orden, su influencia es insospechada porque moldea opiniones e incluso comportamientos, además, contribuye a normalizar en la opinión pública el racismo, el sexismo y la exclusión de la población rural. 


\section{Los medios y la política: ¿Fórmula para la democracia?}

Uno de los ámbitos de mayor presencia y poder de los medios, sobre todo los medios masivos, es el de la política. Es innegable la imbricación entre los intereses de la clase política, de las élites económicas y de los grandes medios. A esta conclusión llega la CICIG en el informe "El financiamiento de la política en Guatemala", publicado en el 2015, donde devela las estructuras y los mecanismos que se han establecido en el país con el propósito de perpetuar la influencia de las élites económicas en los sistemas electorales. Uno de estos mecanismos ha sido, precisamente, el gasto en campañas (particularmente en medios de comunicación), el cual ha adquirido dimensiones millonarias ante la debilidad del Estado y particularmente del Tribunal Supremo Electoral, ente encargado del monitoreo y fiscalización del financiamiento electoral a los partidos.

El informe de la CICIG señala que los gastos en medios de comunicación, principalmente radio y televisión:

Comprenden el pago de anuncios e infomerciales en los medios nacionales (canales de televisión abierta, canales de cable con cobertura en todo el país) y en los locales. La mayoría de municipios cuenta con canales de cable y radios locales en los que se anuncian tanto candidatos presidenciales como candidatos a diputados y alcaldes (30).

Asimismo, se ha desarrollado toda una oferta de servicios, vinculados con medios de comunicación, alrededor de las campañas políticas que incluyen: asesoría de imagen, relaciones públicas, publicidad, producción de anuncios, diseño de vallas publicitarias, manejo de redes sociales (community manager) y elaboración de encuestas para medir la opinión pública.

El papel que los medios han llegado a protagonizar en el ámbito político responde, primero, a la concentración de la propiedad de los medios, sobre todo la televisión abierta y las cadenas radiales; segundo, a la dispersión en los medios locales que limita su fiscalización por parte de la autoridad competente; $y$, tercero, al surgimiento de grupos de medios ligados a líderes políticos, que en la práctica actúan como medios de propaganda (CICIG).

Las consecuencias de esta sinergia entre medios, partidos políticos y élites económicas son graves, como indica el informe de CICIG es "perjudicial... para el orden social y político... que las mismas personas y grupos que concentran el poder económico concentren también el político" (5). Lo anterior es todavía más grave en sociedades como la guatemalteca, puesto que padece las secuelas del autoritarismo y militarismo y ha tenido escaso tiempo y recursos para consolidar la democracia y las libertades ciudadanas, incluidas la libertad de pensamiento, expresión y opinión. 


\section{La opinión pública crítica: Los "otros" medios}

El ámbito público es un espacio de disputa de poder de discursos, imaginarios y de significados. En ese sentido, si bien cuando se aborda el poder de los medios en el debate público, generalmente, se hace referencia a los medios masivos, la mayoría con un perfil empresarial y no social, no puede dejar de mencionarse que también se han desarrollado iniciativas de carácter local o nacional, y con el avance de las tecnologías de comunicación, también en el ciberespacio, cuyo posicionamiento es crítico del status quo.

Desde el reconocimiento de las identidades, de la lucha por la vigencia de sus derechos, mujeres, pueblos indígenas, jóvenes, personas con discapacidad y migrantes, entre otros, han incursionado en los medios, desde la perspectiva tanto de contrarrestar el poder mediático, como de la construcción de una ciudadanía comunicativa que define la comunicación como un derecho humano, el cual impulsa la capacidad de las ciudadanas y ciudadanos para ejercer esos derechos en los medios, haciendo acción política, haciendo valer su mirada del mundo, sus saberes, colocando sus denuncias, demandas o haciendo auditoría social (Mata).

Estos medios se identifican como una comunicación alternativa, popular, social cuyo propósito es informar y comunicar desde otros lugares de enunciación, desde otras experiencias, desde otras lógicas, lenguajes y estéticas. Se plantean como una opción ante la falta de atención de los grandes medios a la cotidianidad de las personas. El perfil de estos medios es que son generalmente autogestionados, o bien, se basan en el trabajo voluntario, están enraizados en las comunidades urbanas o rurales, en los pueblos indígenas. Elaboran sus piezas comunicacionales vinculando la experiencia, las expectativas, las formas coloquiales de las personas en el ámbito local.

También se han desarrollado otros medios más estructurados, cuya característica alternativa reside en la apuesta por un periodismo investigativo, integrados por personas con alto perfil educativo, y que utiliza herramientas tan sofisticadas como las de los grandes medios, pero su agenda temática y su enfoque es de crítica a los poderes establecidos. Estos medios están dirigidos a un público urbano, de clase media, de profesionales y universitarias.

Como puede inferirse, el papel de los medios en el debate público es diverso y depende de cuáles son sus intereses, agenda y enfoque. Es innegable su presencia e influencia en la configuración de la agenda mediática y pública, así como su responsabilidad en la consolidación de la ciudadanía y de la democracia. Compromiso que muchas veces entra en contradicción con su naturaleza como empresas que "venden" noticias e información.

Para todos los medios, masivos o alternativos, los cambios tecnológicos implican un enorme desafío porque deben encontrar las claves para conectarse con sus públicos. Una cuestión clara es que el Estado, en Guatemala, no le apuesta a la comunicación pública, no se garantiza el derecho a la comunicación como un bien ciudadano, 
sino como privilegio de quienes pueden "consumir" información. Lo anterior limita la formación de ciudadanas y ciudadanos críticos que ejerzan las libertades que conlleva el derecho a la comunicación, y que se deje atrás el temor a la libre expresión de las ideas, que se rompa el silencio en un país que durante gran parte de su historia ha sido amordazado.

\section{Guatemala: Entre el silencio, la represión y la libre expresión}

Guatemala ha sido un país de silencio, asociado con el miedo a la represión que constituye una herencia de más de trescientos años de coloniaje y de casi dos siglos de un sistema republicano que nunca se desarrolló completamente porque, sobre todo a lo largo del siglo diecinueve, prevalecieron instituciones y formas de ejercicio del poder que impidieron el fortalecimiento de la ciudadanía. De hecho, la mayoría de la población, las mujeres y los pueblos indígenas apenas adquirieron la calidad de ciudadanas y ciudadanos en la primera mitad del siglo veinte. Lo anterior a nivel formal porque aún en la actualidad no se garantizan plenamente sus derechos ciudadanos. Las libertades de pensamiento, expresión, de prensa y de opinión, asociadas con la democracia como régimen político, han sido severamente reprimidas, se ha excluido de la palabra pública a la mayoría de la población, debido al racismo y a las jerarquías de género que moldean las estructuras sociales.

La historia política guatemalteca ha estado marcada por una sucesión de regímenes dictatoriales, desde el siglo diecinueve hasta 1944, cuando tuvo lugar la Revolución de Octubre, la cual duró una década y significó avances en los derechos sociales y laborales, sobre todo para la población urbana del país. A partir de la invasión estadounidense, en 1954, los derechos ciudadanos fueron coartados nuevamente y la conducción del Estado pasó a manos de gobiernos militares, que implantaron una política contrainsurgente que cobró numerosas vidas y violentó los derechos básicos a la vida, a la integridad, y también a la libertad de expresión. Fue hasta 1984, con la aprobación de una nueva Constitución, que inició un proceso de pacificación que culminó con la firma de los Acuerdos de Paz en 1996. En ese contexto, el surgimiento de medios de comunicación críticos e independientes siempre fue excepcional. Ha sido uno de los rezagos de la democracia que aún no se logra superar.

Al escaso espacio para los medios se suma, en las últimas cuatro décadas, el registro de un largo historial de amenazas, desapariciones y asesinatos de periodistas en el ejercicio de su profesión. Los números son impresionantes, por ejemplo, "entre 1978 y 1981 fueron asesinados 19 periodistas, tres fueron secuestrados, otros tres fueron heridos y cuatro desaparecidos". Entre estos cabe destacar el nombre de Irma Flaquer, cuya vida periodística se extendió durante veintidós años y quien fue desaparecida el 16 de octubre de 1980. 
Tras un breve período de relativa calma, en tiempos de posguerra, la situación no ha sido menos grave, según datos de la Agencia de Noticias Cerigua, "desde el año 2000 a la fecha, 37 periodistas y comunicadores sociales han sido asesinados", hechos que no han sido investigados a profundidad por las autoridades competentes. Asimismo, un importante número de casos tanto de asesinatos como de acoso a periodistas, sucede en los departamentos, como indica Elsa Coronado, citando el informe sobre Libertad de Expresión (Cerigua), la situación de la prensa a nivel departamental es "sumamente peligrosa" y menciona acciones del crimen organizado y del narcotráfico, de políticos locales, alcaldes y diputados que provocan la autocensura, la censura y amenazas contra los reporteros locales. En efecto, cita Coronado:

De las denuncias presentadas por periodistas en 2014, el $50 \%$ involucran a agentes policiales y el resto, a concejales, alcaldes y trabajadores gubernamentales. La coacción y el abuso de autoridad son los delitos más comunes contra los comunicadores, después de las amenazas (s. p.).

La firma de los Acuerdos de Paz, en 1996, significó un primer paso para superar el silencio e iniciar una relativa apertura para la expresión ciudadana. Asimismo, junto con el avance de las tecnologías de comunicación -internet, redes sociales-, se crearon nuevos medios y nuevas formas de comunicación. La voluntad planteada en los acuerdos para fortalecer la democracia ha tenido como uno de sus prerrequisitos el impulso de la ciudadanía, de sujetos de derechos que establezcan nuevas relaciones con el Estado y que desarrollen las capacidades para generar y expresar opinión ante los asuntos públicos, así como de ejercer el derecho a la auditoría social.

No obstante, los innegables avances que se observan en el creciente número de medios alternativos, tanto a nivel urbano como rural, en propuestas innovadoras que aprovechan las nuevas tecnologías de comunicación, en las capacidades de grupos y movimientos para difundir sus ideas y propuestas, el ejercicio de los derechos a la comunicación, enfrenta obstáculos como el persistente analfabetismo, la pobreza, la escasa formación ciudadana, el autoritarismo y las secuelas del conflicto armado. Asimismo, es un reto la concentración de los medios masivos de comunicación en manos privadas, así como la inexistencia de medios de comunicación públicos que brinden espacio para que las y los sujetos, grupos y pueblos dispongan de canales de expresión respetando la diversidad idiomática característica de esta sociedad.

En ese contexto, el papel de los medios de comunicación ha sido complejo porque, como plantea Califano: "más allá de su lugar como intermediarios entre los hechos y las audiencias, los medios de comunicación son actores políticos con intereses particulares que se mueven en un campo atravesado por relaciones de poder". Esas relaciones de poder son marcadas por las élites económicas, por la clase política y, durante gran parte de la historia del país, por el ejército como institución relacionada con 
el ejercicio del poder estatal desde la lógica de la doctrina de la seguridad nacional, que se basa en el control de la ciudadanía.

\section{¿Cuál ha sido la agenda de los medios?}

Al hacer una lectura de los últimos treinta años se perfila un antes y un después de la firma de los Acuerdos de Paz. Durante las décadas anteriores a este acontecimiento, los medios estaban sujetos a una política estatal configurada a partir de la idea de un "enemigo interno" que justificaba el control militar porque, desde la perspectiva de la guerra fría impuesta desde los años cincuenta, la nación y el Estado estaban en peligro ante la invasión comunista. Al respecto, el sociólogo Héctor Rosada plantea que desde 1954 se empezó a perfilar un "ejército anticomunista" que posteriormente fue protagonista de varios golpes de Estado y que en el período de finales de los ochenta hasta 1982 actuó desde una lógica contrainsurgente. A partir de 1983 y hasta los años noventa fue transformando su postura hacia una institución que propició la transición a la democracia.

La referencia a la institución militar es obligada por su enorme peso en la dinámica social, ideológica y política que permeó a toda la sociedad y la agenda de los medios no estuvo exenta de la influencia de ese poder. Como plantea Sagastume al analizar la cobertura periodística de las masacres ocurridas en el período 1982-1983, con el propósito de orientar la opinión pública, las instituciones estatales "usaron como canales los medios informativos y las escuelas. A los cuales se les aplica censura (cuando sea necesario), se promueve la autocensura y se eliminan medios contrarios al gobierno" (5). Este mismo autor cita a un periodista de esa época quien plantea:

El dueño tomaba la decisión de que eso no saliera publicado, que en esas épocas los dueños eran los directores, o el jefe de redacción era el que tenía el filtro y después el mismo reportero. Que decía, bueno si yo publico esto me pueden matar (5).

En ese contexto, el control del espacio político dejaba un margen muy estrecho para la libre expresión, la voz hegemónica era militar:

La represión, la poca profesionalización y la corrupción, determinaron la fabricación periodística. De tal cuenta, por ejemplo, el Ejército apareció citado en 18 de las 20 notas (referidas a las masacres, asm) sin contraste alguno. Esto le confirió la posibilidad de monopolizar el discurso público (Sagastume 9).

Como ya se planteó la agenda de los medios, supeditada al Estado y su política contrainsurgente, empezó a cambiar en 1985 con la recuperación de cierta institucionalidad democrática y se profundizó con la firma de los Acuerdos de Paz una década después. El control férreo de los medios empezó a distenderse y se fue instalando una 
incipiente cultura de la denuncia, de la opinión pública, del periodismo investigativo que implica un ejercicio periodístico más profesional, contrastar fuentes y abrir espacios para otras voces que habían estado excluidas del espacio público y político. En ese período los medios empezaron a desarrollar su función con menos presiones y a asumir un rol de auditoría social, para algunos "poco templado y demasiado iracundo" (Monzón 21), pero que indudablemente ocupa un lugar importante en la vida política actual. Las personas empezaron a experimentar la libertad de opinar, más allá de sus círculos familiares, de ejercer esos derechos a la comunicación largamente reprimidos.

Además, con el surgimiento de internet, específicamente de las redes sociales, la inmediatez y la interacción comunicativa cobraron un nuevo significado. Por una parte, porque permiten obtener, e incluso transmitir, información en el instante y, por otro, poder reaccionar a ella en ese momento, todo desde un dispositivo personal móvil. Esto trajo consigo una nueva situación: la sobre información. Cada evento noticioso viene acompañado de una avalancha de información, fotografías, versiones de diferentes medios y personas individuales, de forma que quien recibe esos datos debe discernir entre lo verosímil y lo que no, en un país como Guatemala, la mayoría de las personas no cuenta con las herramientas críticas para realizar este ejercicio y quedan sumidos en la desinformación.

La apertura en los medios, y para los medios, no ha cambiado sustancialmente las jerarquías de poder que siguen marcando la agenda mediática y pública. Ahora operan mecanismos más sutiles y vinculados con la lógica del mercado, pero también con intereses religiosos conservadores y con propuestas políticas de derecha. Como se planteó, se ha establecido una sinergia entre la clase política y las élites económicas que limitan el desarrollo de unos medios autónomos y realmente independientes. A pesar de la creación de medios de comunicación alternativa, estos no pueden competir con los medios masivos y su influencia, por razones obvias, es limitada. Aunque hay mayor diversidad en las fuentes de información, en los perfiles de quienes opinan en los medios y de los medios mismos por la vía de la tecnología, no puede afirmarse que exista democratización en los medios. Se sigue privilegiando el tratamiento de los acontecimientos macro políticos y macroeconómicos, la violencia como hechos aislados, la cultura como folclor, en detrimento de visiones más complejas en términos sociales, históricos y culturales.

\section{El perfil de los medios en Guatemala hoy}

En las líneas que siguen se plantea un perfil de los principales medios de comunicación en Guatemala, el cual evidencia cómo están concentrados en pocas manos, fenómeno que sigue la tendencia a nivel mundial y que es una de las mayores amenazas a la democratización de la comunicación, porque a partir de esos monopolios comunicativos se imponen agendas mediáticas y agendas públicas. 
En el caso de la televisión abierta, según datos de la Superintendencia de Telecomunicaciones (SIT), los 12 canales de televisión abierta han sido otorgados (sin especificar a quién); sin embargo, los canales 3, 7, 11 y 13, los únicos con alcance nacional, son propiedad del empresario mexicano Ángel González, a través de la empresa Albavisión, quien los adquirió a mediados de los años ochenta. ${ }^{1}$ Su programación, como plantea Lucas (10) se reduce a la retransmisión de películas y series estadounidenses, mexicanas y suramericanas. Con lo cual, la característica primaria de la televisión es la escasa producción propia y el alto porcentaje de contenidos extranjeros.

A propósito de esta situación, Becerra y Mastrini escribieron que "probablemente no exista otro caso en el mundo en que una misma persona sea dueña de los cuatro canales privados de VHF existentes" (103). Asimismo, hay concentración en la propiedad de salas de cine y en la distribución de señal de cable, medio este muy extendido y que es distribuido por aproximadamente 386 empresas de distribución de servicio de cable (Barrios).

A pesar del avance tecnológico del medio audiovisual, se observa escaso desarrollo en la producción local ya que muchos de los programas que se transmiten son "enlatados" o siguen patrones importados de otros países. En efecto, Barrios señala que:

No obstante el abaratamiento de los costos de la televisión por cable, y el acceso a una gran gama de canales cerrados. Estos, en su mayoría son extranjeros y poco educativos, los programas presentados no contribuyen a la sociedad. Su programación se enfoca en la captación de audiencia sin conciencia (s. p.).

En diciembre del 2017 el Congreso de la República anunció que lanzaría el Canal 9 y que sería el primero en ser transmitido en señal abierta de forma digital y en alta definición. No obstante, precisamente estas características limitan el acceso para la mayoría de la población, puesto que es necesario que el aparato televisor no sea análogo, sino digital, y con un sistema específico de origen japonés o brasileño (Castañeda). En otras palabras, muy pocas personas tienen acceso a este contenido.

Por aparte, el Canal 5, conocido como TV Maya, está asignado en usufructo a la Academia de Lenguas Mayas (ALMG) por una duración de 15 años, partiendo del año 2012, en seguimiento parcial de los Acuerdos de Paz. Las condiciones formales para la concesión de este canal limitan su desarrollo porque no cuentan con los recursos necesarios para su funcionamiento y, a la vez, "la asignación de la licencia fue acompañada de una prohibición de difundir publicidad y contenido comercial" (Ávila y Gutiérrez 7), de manera que no pueden obtener ingresos, lo cual dificulta su sostenibilidad; además han enfrentado los intereses particulares de gobiernos de turno que intentan apropiarse de la frecuencia. Este canal es el único que transmite en diferentes idiomas mayas, así como información de carácter cultural y educativo. 
Para el caso de la televisión UHF, es decir, de menor alcance que la VHF, la SIT reporta 51 canales otorgados. De los cuales los más conocidos son Guatevisión, con la frecuencia 25, y Azteca Guatemala, con las frecuencias 31 y 35. En ambos casos se trata de televisión comercial. Otros canales relevantes en este formato son el Canal 21, de carácter cristiano, y el Canal 33, que gestiona la Universidad de San Carlos de Guatemala, única universidad estatal.

La televisión, según Ávila y Gutiérrez, es el medio más popular, incluso si no llega a todos los hogares, su contenido tiene mayor penetración en la opinión pública y en el imaginario social, en relación con otros medios de comunicación. Sin embargo, el hecho de que exista un monopolio limita el tipo y contenido de los mensajes que llegan a la mayoría de la población.

Mientras la televisión ganaba popularidad, el medio que la perdía era la radio, después de ser históricamente el que más influía en la opinión pública por su accesibilidad económica y lingüística. Lo anterior no significa que su nivel de penetración sea bajo, puesto que el 98 por ciento de los hogares tienen acceso a ella (Mastrini y Becerra, 2009) y es el único medio masivo cuyas frecuencias pueden transmitir buena parte de sus contenidos en los diferentes idiomas mayas.

La SIT reporta que hasta el 2016 existían 8 radios AM con cobertura nacional, 70 departamental y 14 municipal. Mientras que en FM registran 348 con cobertura departamental y 82 municipal. Un dato a tomar en cuenta es que existe un subregistro, debido a las radiodifusoras que funcionan sin permiso.

Es imposible hablar de radios en Guatemala sin abordar las radios comunitarias, las cuales han librado una batalla en los últimos años para evitar ser perseguidas y criminalizadas. Aunque en los Acuerdos de Paz firmados en 1996 el Estado se comprometió a favorecer el acceso a medios de comunicación para las poblaciones mayas, xinkas y garífunas; los intereses particulares de carácter comercial y político presionan para ir apropiándose de las frecuencias para su uso exclusivo. Según la Asociación Mundial de Radios Comunitarias en Guatemala (AMARC Guatemala), el acceso a las frecuencias de radio, reservando algunas de estas para que sean utilizadas por los pueblos originarios y sectores vulnerables, contribuye a la descolonización y promueve el sentido de pertenencia comunitaria y la identidad.

Estos valores promovidos desde el seno de la comunicación comunitaria, a través de la radio, van a contracorriente de la presión globalizadora que promueve el individualismo y la uniformidad occidental, lo blanco y patriarcal. Las radios comunitarias hacen un ejercicio de resistencia frente a esta situación. César Gómez, de la asociación Sobrevivencia Cultural y experto en radios comunitarias, compartió en una entrevista el esfuerzo continuo de sostenibilidad y de inclusión de los sectores sociales en las radios comunitarias, distribuyendo sus contenidos equitativamente con las siguientes franjas: informativas, de mujeres, de jóvenes, religiosas o espirituales y de entretenimiento. Todo en un contexto de persecución y ataques hacia la libertad de expresión. 
En este breve perfil de los medios, es preciso hacer referencia a la prensa escrita. En este sentido, Mastrini y Becerra hacen una clasificación de acuerdo con la propiedad de los medios impresos, públicos y privados. El carácter público es exclusivo del diario oficial de gobierno Diario de Centro América, mientras que en el sector privado se pueden identificar 10 medios de circulación diaria: Prensa Libre, La Hora, Siglo Veintiuno, El Periódico, Nuestro Diario, Al Día, Publinewws, Soy 502, El Popular y El Quetzalteco.

Los mismos autores señalan que la propiedad de los medios escritos también está concentrada en pocas manos, donde destaca la familia Marroquín. Aunque los índices de lectura señalan que solamente el 3 por ciento de la población guatemalteca lee los periódicos diariamente, también se hace énfasis en que son las personas de la capital, y, en segundo lugar, de Quetzaltenango, con mejores condiciones económicas, quienes tienen acceso a este medio. Según Ávila y Gutiérrez:

En el año 2012, dos nuevas revistas de investigación iniciaron operaciones: Contrapoder y Crónica Guatemala, estas basan su modelo empresarial en la edición impresa, dado que el modelo de revista virtual no genera las ganancias necesarias para constituir un modelo empresarial exitoso (24).

\section{El impacto del internet en los medios}

El desarrollo del internet ha tenido impacto en la prensa impresa, con celeridad los medios impresos tradicionales van incursionando en los formatos digitales. Hasta el momento, la estructura de internet, fuertemente amenazada y encaminada hacia la privatización, ha permitido que nuevos proyectos periodísticos vean la luz, entre los cuales se puede mencionar a Plaza Pública y Nómada. El primero es un proyecto de la Vicerrectoría de Investigación y Proyección de la Universidad Rafael Landívar, jesuita, fundado en el 2011. El segundo inició en el 2014, como "una empresa en la que todos sus accionistas son públicos, que se basa en alianzas institucionales con fundaciones y alianzas comerciales con empresas, a las que les vendemos servicios desde nuestro medio y desde nuestra agencia de contenido, Nueve" (s. p.), según informan en su portal Nómada. Ambos desarrollan periodismo de investigación y gozan de credibilidad entre un público intelectual y universitario.

A propósito de las nuevas propuestas de medios digitales, cabe indicar que según el estudio de Open Society Foundation "Los medios digitales: Guatemala", para el 2013, "solo el 16 por ciento de la población (contaba) con conexión a Internet, y apenas el 1 por ciento (tenía) conexión de banda ancha. El uso del Internet se concentra entre la clase media y los jóvenes urbanos" (Ávila y Gutiérrez 7).

$\mathrm{Al}$ respecto, cabe mencionar que en el 2017, el Alto Comisionado de Derechos Humanos hizo al Estado de Guatemala un cuestionamiento sobre las medidas que ha 
tomado para facilitar y ampliar el acceso de las mujeres a internet, la respuesta fue que "El Estado de Guatemala informa que no existen medidas específicas con relación a facilitar y ampliar el acceso de las mujeres a Internet" (Rodríguez 5) y aunque se cita una política que promueve la equidad en la educación, no se refiere puntualmente al tema tecnológico. En este informe (Rodríguez) se consigna que, según la Encuesta Nacional de Empleo e Ingresos del 2016, el 51 \% de las mujeres indicó no haber utilizado internet; como tampoco lo había utilizado el $71 \%$ de personas indígenas. Por lo que, se deduce que las probabilidades de nunca haber accedido a Internet se incrementan para las mujeres indígenas.

Otra fuente de información sobre uso de TIC es la empresa de investigación digital iLifebelt AC, la cual ha realizado desde el 2011 al 2017 un estudio anual para medir el uso de internet y redes sociales en la región centroamericana. La metodología se basa en una encuesta en línea y algunos datos interesantes son los siguientes: Guatemala es el país con mayor número de usuarios de Facebook en la región, de 1.7 millones en el 2012, aumentó a 4.2 millones en el 2015. El uso de redes sociales, desagregado por género, muestra que ha disminuido la brecha entre mujeres y hombres, en el 2013 la relación era $38 \%$ de mujeres y $62 \%$ de hombres, y para el 2016 el porcentaje de mujeres (51 \%) superó al de hombres (49\%). El perfil educativo de quienes usan las redes sociales muestra que son personas con estudios universitarios un $45.1 \%$ y con estudios de posgrado $12.6 \%$, con educación media $36.9 \%$ y solo con educación primaria $12.5 \%$. Las edades de las y los usuarios de las redes se concentran en los rangos de 12 a 30 años, un $63 \%$ (iLifebelt).

Por su parte, un $54 \%$ se conecta varias veces al día y las razones para hacerlo van desde mantener comunicación con amistades y familiares, leer noticias y compartir fotografías.

En síntesis, como marca la tendencia en otras sociedades, Guatemala presenta un alto consumo de medios digitales, sobre todo teléfonos celulares, computadoras y tabletas, también ha aumentado significativamente el acceso a internet y el número de personas usuarias de redes sociales que en su mayoría son personas jóvenes urbanas, con estudios universitarios y de estratos medio y alto. En ese universo se ha cerrado la brecha de género, pero esta persiste en el área rural y entre mujeres urbanas y rurales.

La transición al internet conlleva sus propios riesgos, los cuales no solo asume el periodismo escrito, sino también el televisivo y radial que migra al medio digital. Uno de estos riesgos es el hackeo a las cuentas de periódicos y periodistas, es decir, una forma de censura. Tanto El Periódico, Plaza Pública como Nómada han reportado caídas en sus sistemas. Otro riesgo es precisamente la monopolización del internet y su concentración en pocas empresas como Google y Facebook. En otros lugares, principalmente en Estados Unidos y Europa, ya se libran batallas legales a nivel de la legislación para permitir que la internet siga siendo libre. Mientras que en Guatemala la 
legislación al respecto es nula o insuficiente, como la Ley de Telecomunicaciones que data del año 1996, cuando no se habían desarrollado las plataformas digitales.

Finalmente, pero como punto clave del presente y el futuro, internet y específicamente la abundancia de redes sociales y páginas web colocan al receptor de la información en una situación intricada: la de decidir qué información es falsa y cuál es verdadera. En un país como Guatemala, con bajos indicadores de calidad educativa, las personas difícilmente logran hacer la diferencia y se encuentran con una gran cantidad de contenido. A este fenómeno se le ha denominado como analfabetismo mediático o informático (Díaz) y constituye un desafío a largo plazo para la democratización de los medios y la consolidación de la ciudadanía comunicativa.

\section{Los medios alternativos, independientes, autónomos: Las otras miradas}

En esta exposición panorámica de los medios de comunicación en Guatemala, en las tres últimas décadas, es preciso mencionar la emergencia de varias iniciativas de carácter autónomo que, si bien marginales en términos de su cobertura y alcance, dan cuenta de la importancia que tiene la elaboración y difusión de mensajes que sean un contrapunto a los discursos hegemónicos.

En esa perspectiva, cabe destacar dos medios feministas que tienen un recorrido de varios años: Voces de Mujeres, en radio, y La Cuerda, medio escrito. El primero fue creado en 1993, cuando aún no se firmaban los acuerdos de paz, y se ha mantenido durante veinticinco años, con el aporte voluntario de más de sesenta mujeres feministas y activistas por los derechos humanos, algunas de ellas con formación en comunicación, pero todas vinculadas con la universidad estatal, desde donde transmiten tres veces a la semana por Radio Universidad. Desde el 2005, han surgido tres programas más, en ese mismo medio, con un perfil similar al de Voces de Mujeres: Mujeres y Universidad, Hablan las Mujeres y Caracoleando desde la Academia.

La Cuerda publicó su primer número en marzo de 1998 y durante veinte años ha mantenido la publicación mensual de este periódico que aborda problemáticas de las mujeres, de los pueblos y en los territorios desde una perspectiva feminista. $\mathrm{La}$ Cuerda promueve la discusión política de una propuesta que surge desde las mujeres guatemaltecas con su diversidad de experiencias, voces y demandas. Ha establecido sinergia con otros movimientos sociales y de pueblos indígenas. Además, ha colocado la urgente necesidad de una transformación radical de las estructuras de poder.

Desde una perspectiva comunitaria, feminista y autónoma, Prensa comunitaria KM 169 documenta y difunde la voz de los pueblos indígenas y sus luchas en los territorios. Trabaja desde una plataforma virtual y se basa en gran medida, en el trabajo voluntario, con la conducción de un pequeño equipo.

En la dinámica de las movilizaciones ciudadanas contra la corrupción que tuvieron lugar en el 2015, surgió Radio Urbana, la cual se transmite por internet y es gestionada por personas de diversos colectivos. 
Desde las comunidades existe una densa red de medios, sobre todo de radio, como la Federación Guatemalteca de Radios Comunitarias que tiene sus orígenes en una iniciativa de la Iglesia católica desde finales de los años cincuenta. Es la más antigua en su campo y enlaza a radios de los departamentos del occidente del país y una del oriente donde habita el pueblo chortí.

En la coyuntura del 2015 también surgió la Red Tz'ikin representa un esfuerzo por comunicar, principalmente desde lo audiovisual, las problemáticas nacionales a nivel comunitario. Creó un programa de televisión comunitaria que se difunde principalmente en internet y en algunos canales comunitarios. Más allá de ser un medio de comunicación en línea, intenta también transmitir algunos audiovisuales en la televisión nacional y ha realizado esfuerzos por crear talleres de video en diferentes regiones del país. Es reconocida también por organizar la Muestra de Cine y Video en Defensa de la Vida y el Territorio dedicada a la difusión en comunidades y escuelas rurales y la Formación y Difusión Audiovisual Comunitaria.

Este es un recuento mínimo de esas otras miradas, pensamientos y voces que, haciendo uso de los medios tradicionales (radio) y modernos (plataformas virtuales, redes sociales, internet), colocan otras problemáticas y propuestas para la transformación social, política, económica y cultural del país.

\section{Los desafíos para una opinión pública crítica}

En Guatemala, la coyuntura política cambió significativamente a partir del 2015, cuando a raíz de investigaciones judiciales, llevadas a cabo por la Fiscalía General con el apoyo de la CICIG, se empezaron a develar los esquemas de corrupción que los diferentes gobiernos han mantenido incluso al más alto nivel. Este secreto a voces, algunas veces denunciado en medios de comunicación alternativos, cobró relevancia a partir de las pruebas recabadas por estas entidades de investigación, provocando la renuncia del entonces presidente y vicepresidenta, así como de numerosos personajes, incluidos empresarios de las élites, vinculados con diversos casos de corrupción.

Desde entonces se ha generado un clima de inestabilidad en el ámbito político, el período presidencial fue concluido, en el 2015, por un presidente interino nombrado por el Congreso de la República, se convocó a nuevas elecciones y el presidente electo, Jimmy Morales, a un año de su mandato, empezó a ser cuestionado por actos de corrupción de familiares inmediatos, pero también "por una investigación de financiamiento electoral ilícito recibido por el oficialista partido FCN-Nación, el cual alcanzaría al presidente Morales y daría pie para que se solicite el retiro de la inmunidad de que goza el primer mandatario" (IPNUSAC 11).

En ese contexto, se han reagrupado las fuerzas políticas que adversan las investigaciones por corrupción porque les afectan directamente y que incluyen, entre otros, a miembros de las élites económicas, integrantes del Ejército e ideólogos 
conservadores. Este círculo de poder, cercano a la actual presidencia, ha tenido impacto en las decisiones gubernamentales que, desde el 2016, están vulnerando el incipiente andamiaje institucional y social que se fue creando desde finales de los años noventa, para dar respuesta a las demandas de garantías de derechos humanos de la mayoría de la población.

En esa perspectiva, todos los derechos están amenazados, incluso desde el Congreso de la República, donde un buen número de diputados y diputadas representa a partidos sobre los que pesan sospechas de financiamiento ilícito y prácticas antiéticas (CICIG). Se ha establecido una sinergia entre estos personajes y quienes defienden una agenda conservadora que pretende un retroceso en los derechos humanos de las mujeres, de los pueblos indígenas, de las voces disidentes. El planteamiento de iniciativas de ley que velada o abiertamente pretenden vulnerar esos derechos, es una muestra de ello.

En particular los derechos de libertad de expresión, opinión e información están amenazados, lo cual es evidente en las intimidaciones y acoso a los medios y periodistas independientes, en las dificultades para la sostenibilidad de dichos medios, así como de las organizaciones que defienden derechos humanos. Una muestra de las pretensiones de los espacios de poder para limitar la libertad de expresión fue evidenciada por los periodistas Ángel Sas y Coralia Orantes del periódico Nuestro Diario, quienes, en agosto del 2018, publicaron una crónica sobre el avance de la vigilancia masiva por parte del gobierno de Guatemala, hacia personas vinculadas con organizaciones sociales críticas, funcionarias y funcionarios, personajes políticos opuestos al gobierno e incluso funcionarios internacionales. En su reportaje desglosan el catálogo de software y hardware adquirido con fondos del Estado valorados en alrededor de 12 millones de dólares (Ipandetec).

La historia del país muestra los efectos perniciosos de la violación a los derechos a la comunicación, como sucedió en el marco de un conflicto armado que permeó a toda la sociedad guatemalteca. Asimismo, y a pesar de los innegables avances en el reconocimiento de derechos, es evidente la persistencia de jerarquías de poder, de brechas de género y etnia, la exclusión de los pueblos indígenas del ámbito público. El debate político continúa dominado por una visión hegemónica elitista que invisibiliza y niega capacidad de agencia y de discurso a esos otros excluidos. Es responsabilidad de los medios, sobre todo masivos, la reproducción de prejuicios y estereotipos, en esos discursos, imaginarios y representaciones sociales. También es un compromiso del Estado promover medios de carácter público que posibiliten la expresión ciudadana.

Para Guatemala es indispensable avanzar en la construcción de políticas públicas que hagan viable la democratización de los medios y el cumplimiento de los Acuerdos de Paz, lo cual permita, además, la libre expresión de los sectores históricamente marginados. La descentralización de los medios también pasa por la creación de normas antimonopólicas y de estándares de comunicación con representatividad. 
No es posible consolidar una democracia sin contar con medios independientes, no es posible construir una opinión pública crítica, sin las mínimas garantías para la expresión de la ciudadanía.

\section{Nota}

Cabe anotar que, según la investigadora Cecibel Lucas, el empresario Ángel González también es propietario de medios en varios países de Latinoamérica: "En Nicaragua tiene los canales 4 y 10; posee acciones en el sistema mediático de Costa Rica en los canales 4, 6 y 11. Las propiedades de González en el entorno de las comunicaciones han ido extendiéndose por toda la región latinoamericana y se calcula que tiene al menos 20 estaciones televisivas. En Ecuador tiene los canales 4 y 5; en Perú, los canales 9 y 13; en República Dominicana provee de programación a los canales 2 y 11. En el sur de México tiene 5 canales. En Argentina adquirió el $80 \%$ de las acciones del canal 9 y con ello se hizo con la gerencia del canal" (19).

\section{Bibliografía}

AMARC. Derecho a la comunicación en Guatemala ipara quiénes? Guatemala: Cholsamaj, 2014.

Ávila, R. y Gutiérrez, A. Los medios digitales: Guatemala. Guatemala: Open Society Foundations, 2013.

Barrios, A. "Historia de la televisión en Guatemala". El Librepensador. Junio de 2011. Recuperado de https://www.ellibrepensador.com/2011/03/11/historia-de-la-television-en-guatemala/

Califano, B. Los medios de comunicación, las noticias y su influencia sobre el sistema político. Revista Mexicana de Opinión Pública, (2015):61-78.

Castañeda, J. Congreso estrena canal de televisión, pero hay que pagar para verlo. Recuperado de http://www.soy502.com/articulo/congreso-estrena-canal-television-abierta-pero-nosera-todos-63338

Cerigua. Los medios de comunicación están en deuda con la equidad de género. Recuperado de https://cerigua.org/article/los-medios-de-comunicacion-estan-en-deuda-con-la-e/

Comisión Internacional contra la Impunidad en Guatemala. Financiamiento de la política en Guatemalar. Guatemala, 2015.

Coronado, E. Cinco fiscales para atender 130 denuncias de periodistas. Plaza Pública. 13 de abril de 2015.

Díaz, B. Analfabetismo mediático funcional. Unesco, 2011.

iLifebelt. Estudio de redes sociales en Centroamérica y el Caribe. 2016. Recuperado de https://ilifebelt.com/estudio-ilifebelt/

Ipandetec. Instituto Panameño de Derecho y Nuevas Tecnologías. 2018. Recuperado de https:// www.ipandetec.org/2018/08/17/el-gobierno-de-guatemala-nos-espia/

López, J. I. Manual urgente para radialistas apasionados. Ecuador, AMARC/FIP/ERBOL, 1997.

Lucas, C. Génesis y evolución de la televisión en Guatemala. Revista Razón y Palabra, 72(15): 2010.

Mastrini, G. y Becerra, M. Los monopolios de la verdad. Buenos Aires: Prometeo, 2009.

Mata, M. C. Comunicación y ciudadanía. Problemas teórico-políticos de su articulación. Revista Fronteiras, 8(1): 2006. 5-15. 
Monzón, A. S. Memoria del porvenir: 10 años de Voces de Mujeres. Guatemala, 2003.

Pareja, N. y Echeverría, M. La opinión pública en la era de la información. Propuesta teórico-metodológica para su análisis en México. Revista Mexicana de Opinión Pública, 2014. 51-68.

Rodríguez, C. (1999). Taller sobre Género y Comunicación. Guatemala, 1999.

Rodríguez, Carla. Oficina del Alto Comisionado para los Derechos Humanos. Recuperado de https:// www.ohchr.org/Documents/Issues/Women/WRGS/GenderDigital/Guatemala.pdf

Rosada, H. Declaración e inicio de interrogatorio de Héctor Rosada Granados ante el Tribunal Tercero de Sentencia Penal. Guatemala, Corte Suprema de Justicia, 2002.

Sagastume, J. Las masacres ocurridas durante el mandato de Rios Montt que tuvieron cobertura en los medios impresos (Tesis de licenciatura). Universidad Rafael Landívar, Guatemala, 2018.

Superintendencia de Telecomunicaciones. Superintendencia de Telecomunicaciones. Recuperado de https://sit.gob.gt/download/canales-de-television-autorizados-en-banda-vhf/?wp dmdl $=2065$

Trujillo, S. "El racismo y la discriminación que no nos espanta". EsQuisses, 2017. Recuperado de: http://www.esquisses.net/2017/06/el-racismo-y-la-discriminacion-que-no-nos-espanta/

Ana Silvia Monzón. Guatemalteca. Socióloga, investigadora y comunicadora feminista. Doctora en Ciencias Sociales, por el Programa Centroamericano de PostGrado, FLACSO. Docente e investigadora en la Universidad de San Carlos de Guatemala y en FLACSO-Guatemala. Es co-coordinadora del Programa Género y Feminismos en FLACSO-Guatemala. Fundadora del Centro de Estudios de las Mujeres y Feminismos, Escuela de Ciencia Política-USAC, 2017. Secretaria Técnica de la Mesa Nacional de Educación Integral en Sexualidad. Co-coordinadora del GT Feminismos y resistencias emancipatorias, e integrante del GT Economía Feminista, de CLACSO. Presidenta de la Asociación Centroamericana de Sociología-ACAS, 2018-2020. Integrante del Comité científico Asesor, programa MOST-UNESCO 2015-2018. Delegada por Centroamérica a la Junta Directiva de la Asociación Latinoamericana de Sociología-ALAS, 2013-2015. Presidenta de la Junta Directiva de Action Aid-Guatemala.

Correo: anas.monzonm@gmail.com

ORCID: 0000-0001-5872-1300

Linda García Arenas. Guatemalteca. Periodista, licenciada en Ciencias de la Comunicación y estudiante de la Maestría en Investigación por la Universidad de San Carlos de Guatemala. Actualmente es la presidenta del Movimiento ATD Cuarto Mundo en Guatemala, catedrática en la Universidad Mariano Gálvez y Especialista en Manejo de Redes Sociales en ChildFund. Forma parte de las colectivas Ciberfeministas 
Guatemala y Voces de Mujeres, es cofundadora de la Biblioteca Paco Piñas. Fue coordinadora del Programa de Comunicación y Cultura Libre del CEPPAS y ha sido consultora para organizaciones de derechos humanos en comunicación e investigación. Correo: lindaura.gare@gmail.com

ORCID: 0000-0001-8851-840X 